\title{
Cabeça Dizpensa, corpo desvago: experimentações de um Laboratório de Sensibilidades
}

\author{
Alexandre Oliveira Henz, ${ }^{I, \star}$ Andre Rodrigues, ${ }^{I}$ Angela Aparecida Capozzolo, ${ }^{\prime}$ Carlos Eduardo Alves Santos, ${ }^{I}$ \\ Eliana Rocha de Lima, I Gustavo Lucas Bardelli de Cordeiro, I Harete Vianna Moreno, I Lara Aparecida Machado \\ Almeida, I Maria José da Silva, ' Rafaela Camargo Baldo, II Sidnei José Casetto, I Tahamy Louise Duarte Pereira, \\ Thayara Paule Herrera Lima ${ }^{I}$ \\ ${ }^{I}$ Universidade Federal de São Paulo, Santos, SP, Brasil

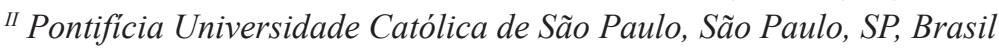

Resumo

O Laboratório de Sensibilidades da Universidade Federal de São Paulo (UNIFESP) é uma tentativa de construir experimentos abertos às alteridades, com ações em diversas superficies que podem reverberar dentro e fora de seu lugar material. Neste artigo expomos algumas experiências que transversalizam o corpo desvago do Laboratório e suas incidências nos corpos que o compõem e decompõem. Narramos uma experimentação com uma comunidade-corpo, que se modulou em uma performance que nomeamos coletivamente de "Cabeça Dizpensa". Discutimos, dentre outras, as noções de intervenção e interferência, e um itinerário de problematizações e pequenas narrativas com ecos do laboratório.

Palavras-chave: Laboratório de Sensibilidades; corpos; experimentação; interferência.

\section{Lo(o)se-Head, diffuse body: experimentations with a Sensitivities Laboratory}

\begin{abstract}
Sensitivities Laboratory at Federal University of São Paulo (UNIFESP) is an attempt of creating experiments that are open to alterities, with actions in many different surfaces which can reverberate into and out of its material place. In this paper we expose some experiences that transversalize the Laboratory's diffuse body and their incidences in the bodies that compose and decompose it. We report an experimentation with a community-body, which has shaped into a performance we collectively named "Lo(o)se-Head". Among others, we bring the discussion of the notions of intervention and interference, as well as an itinerary of questionings and short narratives that bring echoes from the Laboratory.
\end{abstract}

Keywords: Sensitivities Laboratory; bodies; experimentation; interference.

As conchas são os ossos do oceano, disperso esqueleto, desvago. Guimarães Rosa.

\section{Preliminares}

Num dia desses, entrando em um shopping qualquer, noto que minha passagem para dentro do prédio era marcada por uma cortina de ar, tão sorrateira quanto constante. Senti-me entrando em um laboratório daqueles brancos, com um cheiro amargo de limpeza, onde todo tipo de ruido permitido parece surgir de caixas de som instaladas: objetos metalizados, animais farfalhando em gaiolas, jaleco raspando pelos cotovelos. Era como se as condições fossem milimetricamente filtradas para que tivesse inicio algum experimento sem fim. Controlam-se os microrganismos no ar, a iluminação, a alimentação, o tempo de permanência em frente aos vidros, o limite dos espaços, a cintilância dos objetos. Durante a dita purificação corporal, tornar-nosiamos livres para medir e consumir os valores segundo nossas vontades mais conscienciosas. O ar-condicionado mantém a temperatura constante, há uma miriade de silenciosos aparelhos que detectam, acompanham e

\footnotetext{
^Endereço para correspondência: Universidade Federal de São Paulo, Departamento de Ciências da Saúde. Av. Ana Costa, nº 95 - Bairro Vila Matias. Santos, SP Brasil. CEP: 97015-372.E-mail: alexandrehenz2000@yahoo.com.br, dreepsico@ hotmail.com, angeruma@uol.com.br, carloslhd@gmail.com, elianarocha810@ gmail.com, gugalucas0@gmail.com, harete@uol.com.br, lara.almeida96@yahoo. com.br,majosil@uol.com.br,rafaelacamargob@gmail.com,sidneicazeto@uol. com.br, tahamy.pereira@gmail.com, thayara.paule@hotmail.com
}

aplainam oscilações conforme as várias médias definidas e modificáveis. Nossos órgãos se adaptam a tais modulações tendendo a avaliar as oscilações a partir dessas médias do que já estamos acostumados e do que vai se acostumando em nós. Os corpos se tornam lâminas em justaposição, havendo sempre uma superficie a ser conquistada e modulada; multiplicam-se as taxas, o leque de controle segue seu desdobramento, média ao lado de média: arcondicionado, colesterol-condicionado, lactobaciloscondicionados, investimento-retorno-condicionados, serotonina-condicionada, hora-de-acordar-condicionada, número-de-palavras-em-uma-frase-condicionadas, satisfação-própria-condicionada etc.

Mas há um outro tipo de experimento em laboratório em que se tenta habitar, algo como um estúdio de produções abertas. Uma faixa sonora se desprende com a fricção entre focos de alteridade impossíveis de identificar, as oscilações são elas mesmas avaliações, quem experimenta é intérprete de uma música que não se sabe de onde veio nem quando se iniciou. Essas fugas sonoras não respeitam as paredes cronológicas, muito menos as de concreto e provocam descompassados. Uma síncope dos sentidos acompanha a aparição de corpos em nós: nossos corpos tornamse possuídos por movimentos inusitados, o pensamento dispensa coisas imprescindiveis para um tipo de vida, a língua arrisca-se em gestos no limite do suportável, contornando desconcertada as beiradas do menos de tudo 
que se é. Aqui a alma é um estômago ${ }^{1}$ e seu regime é uma brincadeira séria.

Ao engendrar performances, perturbações, ambiências, o Laboratório de Sensibilidades (LS) procura ser um lugar para estas possibilidades, de modo a criar espaços de germinação e espraiar-se. O LS tem se constituído em um folheado: ensaios e oficinas de dança, experimentos e oficinas abertas com performance, o grupo de estudos (GELS), o grupo de articulação do LS - que agencia ações no campus, em estágios e com coletivos de artistas - um blog com efeitos dentro e fora da UNIFESP e ações nos módulos de graduação e seminários de pósgraduação com incidência na formação de profissionais da rede de assistência social, saúde, saúde mental e educação. Alguns egressos, por exemplo, que passaram pelo Laboratório, referem as marcas das experimentações com o Clube dos Saberes, ${ }^{2}$ de que agora lançam mão nos serviços das redes da Saúde Mental e Assistência Social, em proposições intergeracionais e com agenciamentos entre profissionais e movimentos sociais.

Reunimos narrativas recortadas e espalhadas que aqui arranjamos em um conjunto heterogêneo. Por isso, diferentes tempos verbais podem se misturar, sem linearidade ou sequência cronológica. Passado e presente, juntos na mesma folha, orientam-se pelos fluxos de pensamento e das experiências que nos atravessam, permitindo entrever espaços-tempos que nos acompanham.

\section{Cabeça dizpensa}

como dizer - ao ver -
entrever -
crer entrever -
querer crer entrever -
isto de querer crer entrever o que onde
Samuel Beckett

Era início de 2012, e ocorria a desocupação do prédio da Ponta da Praia - uma das unidades do campus Baixada Santista, espaço em que estava o Laboratório de Sensibilidades. A mudança ocorreria para o prédio na rua Silva Jardim, recém-construído para abrigar aulas e diversos laboratórios (dentre eles o LS), bem como a biblioteca e o restaurante universitário. Após a saída do prédio da Ponta da Praia, soubemos que o andar da Silva Jardim em que ficaria o Laboratório ainda estava em obras e levaria algum tempo para ficar pronto. Um incidente com a cobertura de gesso do teto, após um dia

\footnotetext{
'Acerca de essa questão ver também a instalação " $A$ alma é um estômago: relato de um visitante" (LABORATÓRIO DE SENSIBILIDADES, 29 abr. 2016a). Cf. Ferraz (1999, p. 32, grifo do autor), "o tema da função digestiva do esquecimento se relaciona diretamente à seguinte afirmação do parágrafo 16 do capítulo 'Das velhas e novas tábuas' de Assim falou Zaratustra III: 'o espírito é um estômago', em que o 'é' foi destacado por Nietzsche. Trata-se, também nesse trecho, de enfatizar que, mesmo em um texto como o Zaratustra, não se trata aqui de uma metáfora, de uma simples analogia. O espírito não é semelhante a um estômago; espírito e estômago se fundem: [A alma é um estômago]".

${ }^{2} \mathrm{O}$ trabalho com o Clube dos Saberes foi sustentado pelo laboratório e é atualmente um dispositivo utilizado por egressos da UNIFESP em equipamentos da Assistência Social e Saúde Mental da Baixada Santista. As primeiras experiências do Clube na UNIFESP e do próprio Laboratório foram analisadas no escrito: Laboratório de Sensibilidade, Inteligência coletiva e Clube dos saberes (CASETTO et al., 2007)
}

de chuva, mostrou que havia readequações estruturais que precisavam ser feitas para que fosse seguro habitá-lo. O LS ficou, então, sem espaço físico por alguns meses.

Nesse meio tempo, começamos ${ }^{3}$ a pensar em uma reinauguração para quando o Laboratório estivesse pronto. Durante a preparação, lembrávamos que ocorrera uma performance inaugural ${ }^{4} \mathrm{em} \mathrm{2007}$. Nesse recomeço pensávamos que uma produção coletiva poderia marcar esta nova chegada. Alguém trouxe a foto da obra de Lygia Pape, O Divisor, que é a montagem de um corpo coletivo público. Um tecido com fendas na superfície com muitas cabeças, um corpo aberto andando sem uma cabeça única guiando.

Em outra semana, assistimos o vídeo da bailarina e coreógrafa portuguesa Vera Mantero: Vamos sentir falta de tudo aquilo que não precisamos em que os participantes apareciam com cabeça de manequim de onde retiravam coisas em silêncio. Também a problemática do "comum" como uma espécie de categoria política e clínica estava presente em nossas problematizações. Ao mesmo tempo, vínhamos trabalhando com a noção nietzschiana de que A alma é um estômago, isto não é uma metáfora (LS, 2012) e com as antropofagias. Interessaria uma seleção nutricional, ético-política, que experimenta e interfere com diferentes regimes: comer certas coisas, outras não, privar-se do que nutre alguns tipos de órgãos, arriscar o paladar com pratos atípicos, abster-se do cardápio do dia, exercitar músculos em jejum etc.

Isso tudo foi se recombinando em nós ao modo da estratégia de William Burroughs (1994, p. 57) que anotava no que mais apreciava, as iniciais GETS, de Good Enough to Steal: bom o bastante para roubar, pois apostávamos no roubo de partes, de fragmentos criteriosamente rapinados que constituíram os elementos pelos quais, ou que em seus intervalos, tivemos acesso a sons e imagens que interessavam.

Parecia-nos boa a cena de tirar coisas das cabeças; as do vídeo eram grandes, semelhantes a de manequim. Pensamos que cabeças de boneca de tamanho grande, de plástico e porcelana, funcionariam para a nossa performance - embora ainda não a chamássemos assim. Aos poucos começaram a habitar o Laboratório cabeças de boneca, que iam fazendo parte de uma decoração algo bizarra: cabeças, cabeças, muitas cabeças. A foto de $O$ Divisor também ficava à vista. No processo da produção da performance, a ambiência do Laboratório sofreu torções: virou depósito de bonecas, panos variados, cozinha improvisada, materiais de umbanda etc. Surgiu a ideia de uma espécie de cortejo com o longo pano branco translúcido, com aberturas para deixarmos as cabeças de fora, em que carregássemos as outras cabeças.

\footnotetext{
${ }^{3}$ A narrativa segue na primeira pessoa do plural, que se refere ao coletivo que compõe o grupo de articulação do Laboratório de Sensibilidades.

${ }^{4}$ Ocorrida em 12/03/2007, a inauguração do Laboratório de Sensibilidades abriu o espaço com uma performance. Os registros em vídeo e uma narrativa deste momento estão disponíveis em Laboratório de Sensibilidades 2007: primeiro dia (LS 2011).
} 
O tempo que levamos digerindo nossas múltiplas questões e gestando a reinauguração não nos é claro, mas a lembrança que acessamos é de que o caminhar foi lento. Muitas vezes parecíamos falar novamente as mesmas coisas: "será que entramos em looping?" Alguém dizia ou trazia algo inédito, ou ainda alguém ouvia como inédita alguma coisa já diversas vezes enunciada. Produziam-se então diferenças. Retornávamos.

Num dado momento, decidimos uma data. Isto ajudou a trazer a produção para um plano de atualização de quais agenciamentos precisamos para que aconteça? Definimos quais objetos sairiam das cabeças; pensamos em convidar a bateria da UNIFESP - Repicapau - para acompanhar; "que tal um bolo-intestino? Vi ontem à noite na TV Folha". Resolvemos usar TNT branco e translúcido emendado com cola quente para fazer o nosso Divisor e pensamos em grudar pegadas no chão, mostrando o caminho do saguão até o LS, no terceiro andar. A reinauguração tomava delineamentos, e seguiu se formando até o momento de acontecer.

05 de dezembro de 2013: Em uma das paredes do saguão da Universidade, um pano anunciava o nome da produção: Cabeça Dizpensa.

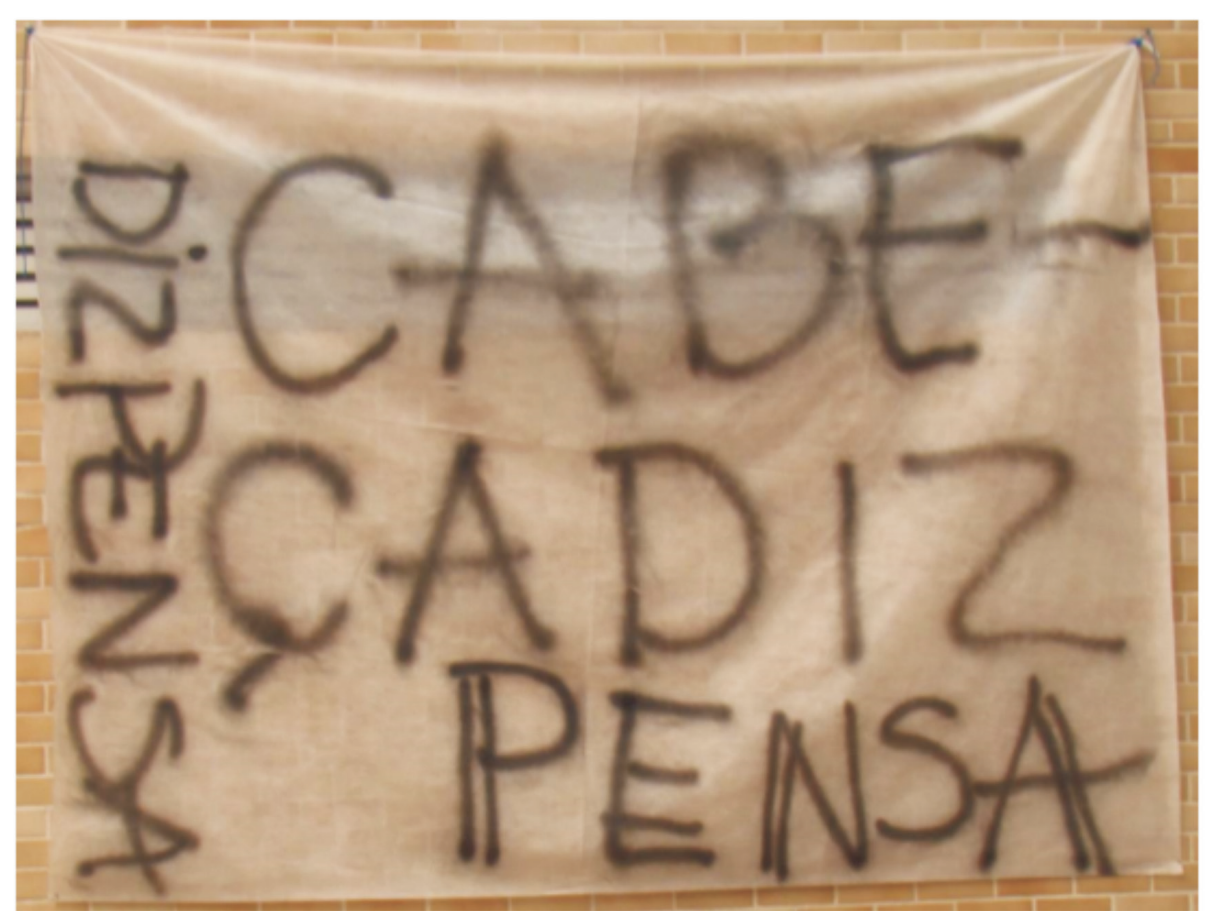

Cabeça-despensa com 's', é um verso, slogan, verbete, anti-slogan de Palavra Desordem de Arnaldo Antunes (2002). O enunciado pairou na conversa conseguindo reunir tantos sentidos daquilo que estávamos construindo, gestando, ruminando há tempos. Essa performance também carregava marcas de ações anteriores do projeto de extensão Literatura e Clínica, ${ }^{5}$ ligado ao Laboratório. De início se chamava "Palavra", em seguida Despalavra. A brincadeira ressoava com um movimento nosso de

\footnotetext{
${ }^{5}$ Houve um período em que o Laboratório de Sensibilidades foi um projeto de extensão articulado com outros projetos, como o Cinema e Saúde e o Literatura e Clínica. Acerca da experiência do Literatura e Clínica ver especialmente Henz et al. (2012).
}

esvaziar, de dispensar, tirar o excesso daquilo que não precisamos e sentiremos falta, como diz o subtítulo do trabalho de Mantero.

Corpos quaisquer disponíveis à experimentação: uma aposta política. Tomando emprestada uma frase de Deleuze e Guattari (1966) ainda que um pouco modificada, ${ }^{6}$ poderíamos dizer que antes do corpo há a política e que o corpo é político. $O$ divisor de Lygia Pape parece ser um experimento desta ordem, talvez uma comunidade-corpo provisória e acéfala. ${ }^{7} \mathrm{Um}$ devir imperceptível, experimentado em algum momento pelos corpos abertos, na condição de acéfalos.

$\mathrm{Na}$ performance brincamos com trocadilhos e ditos populares como "está faltando um parafuso na sua cabeça" ou "limpar a mente" ou ainda "lavar a alma". Retiramos das cabeças signos e objetos: dinheiro, moedas, uma pequena cabeça de Barbie (extraída com uma pinça); também remédios, farinha, carrinhos, cruzes, até minhocas. Por fim, uma cabeça de boneca de porcelana escapa das mãos e se estilhaça.

Assim, nessa performance que engendramos, cada um carregava sua cabeça paradoxalmente, debaixo do pano. Não ocupamos todos os buracos para poder receber quem quisesse entrar. Cada um ocupou um espaço e outros se uniram a nós em dissonâncias, mantendo um fluxo de movimento com o tecido numa espécie de composição com os corpos; era preciso perceber o tempo e o ritmo do outro para juntos avançarmos. A pequena caminhada pelo saguão da universidade exigiu um exercício de perceber as temporalidades, as respirações, ajustes de alturas e distâncias, a partir de uma certa negociação coletiva silenciosa. Era preciso acionar sentidos do corpo, tatear com os poros, os fluxos e a cadência da Bateria. ${ }^{8}$

Um a um se retirava da comunidade-corpo provisória e acéfala e se deslocava à sua maneira até onde iria

${ }^{6}$ A frase referida é "antes do ser há a política" (DELEUZE; GUATTARI, 1996, p. 78). ${ }^{7}$ Várias manifestações contemporâneas contra o golpe de 2016 no Brasil têm uma configuração acentrada e acéfala sem o grande líder encabeçando ou o partido-guia. Nessa questão há também ecos da revista Acéphale publicada (originalmente em janeiro de 1937) por Georges Bataille, Pierre Klossowski, André Masson, Jean Wahl, Jean Rollin, bem como do escrito Polegarzinha de Michel Serres (2013, p. 37) com a cabeça fora do pescoço: "Agora, a cabeça decapitada da Polegarzinha se diferencia das antigas, podendo ser mais bemconstituída do que cheia. Não tendo mais que se esforçar tanto para armazenar o saber, pois ele se encontra estendido diante dela, objetivo, coletado, coletivo, conectado, totalmente acessível, dez vezes revisado e controlado; ela pode voltar sua atenção para a ausência que se mantém acima do pescoço cortado. Circula por ali o ar, o vento".

${ }^{8}$ A Bateria RepicaPau da UNIFESP pode ser vista e ouvida no registro em vídeo intitulado Cabeça Dizpensa: grupo de articulação do laboratório de sensibilidades (LS, 2016b). A performance durou cerca de 20 minutos. 
fazer sua ação. As cabeças, então esvaziadas de suas coisas, eram deixadas no chão e cada um seguia o percurso até retornar ao pano, onde reinseria sua própria cabeça. Uns cambalearam, outra foi lentamente, uma se arrastando, alguns firmes em seus passos, cada passada ia à sua batida de pisada. Tantas cabeças esvaziadas, corpo desvago, era um. No chão, ia se formando uma espécie de despacho de tudo aquilo que não precisamos $e$, entretanto, sentiremos falta. Retiramos o pano branco dos ombros e estendemos por cima do feito, minhocas, farinha, espuma e todos os outros objetos retirados. A bateria silenciou seu batuque e seguimos nos misturando aos que assistiam; mais um, "qualquer" um que deixa seu feito e continua no jogo do comum.

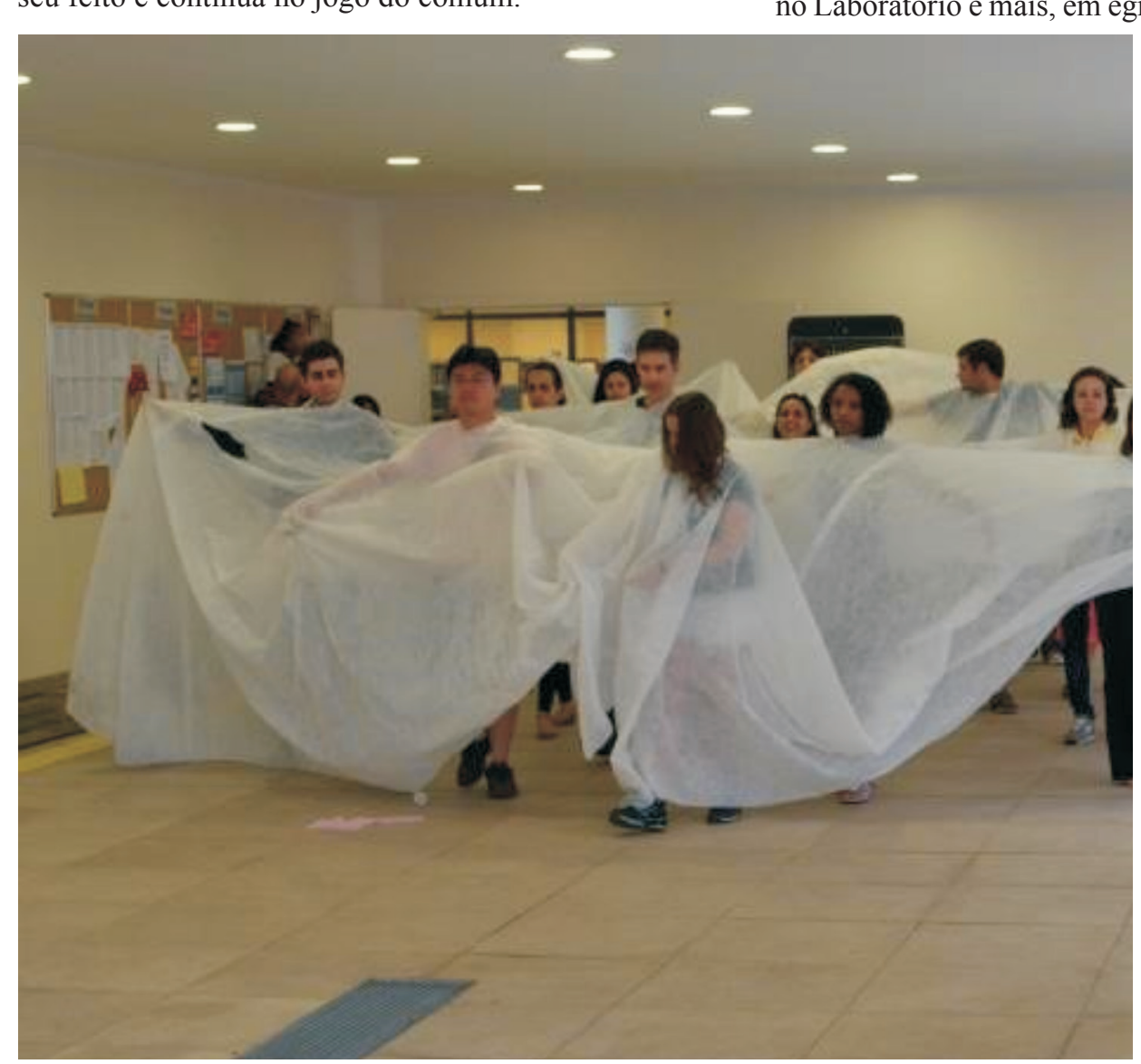

\section{Bastidores: a feitura do artigo}

Existe a procura por um autor e existe a procura do-(s) autor - (es). ${ }^{9}$

Peixoto

No decurso de um tempo fizemos reuniões, percorremos juntos piscinas de silêncio, produzimos narrativas que contornaram e irrigaram algumas experiências do Laboratório dentro da sala e fora em seus transbordamentos sutis. Um dos primeiros movimentos foi cada um enviar para os outros fragmentos de narrativas, ao mesmo tempo coletivas e singulares relacionadas às experiências do Laboratório, e, então, foram se delineando diferentes encontros de textos que por fim se apresentaram neste artigo, dispersos, desvagos.

\footnotetext{
${ }^{9} \mathrm{O}$ plural foi adicionado pelos autores do texto.
}

Integram o escrito alunos da graduação, egressos, professores, residentes, mestrandos, trabalhadores da rede; juntos, pesquisadores. Todos pondo a mão na massa, aquela do bolo antropofágico, feito de açúcar impalpável, ${ }^{10}$ trazendo ideias, autores, contaminações, imagens, instantâneas comunicações, cadernos de anotações, envio de problemas e silêncios.

Nos bastidores deste escrito, produziu-se uma zona intermediária, uma meticulosa e paciente tentativa de preensão das nuvens de experiências do Laboratório em lugares em que dele nunca se escutou falar. O coletivo de escrita, em deambulação, trabalhou ao modo de um sismógrafo sondando cenas que eram ondas que estavam no Laboratório e mais, em egressos, estágios, módulos de graduação, pós-graduação e serviços, de forma menos direta e explícita. Eram intervenções e interferências e foi preciso trabalhar com fragmentos narrativos editados, embaralhados, riscados, várias vezes reescritos.

Percebemos que nem todas as experiências que aparecem no artigo se deram no espaço do Laboratório. Inversamente, nem todas as inquietações políticas e conceituais dos grupos de Estudo e Articulação, que comparecem nesse escrito, ganharam ecos em experimentações, instalações, dispositivos ou performances.

Tomamos experiências estéticas, as experiências com as artes como produtoras de pensamento, operadores de pesquisa, em contraste com a distinção hierarquizada entre a área da ciência como um bloco (sério e de valor) e o setor da arte-cultura que seria outro bloco, ligado à fruição.

\section{Interferências e intervenções}

Partimos de uma distinção entre a noção de intervenção e a de interferência (INFORSATO, 2010). Seria preciso pensar as interferências ao modo das ondas de rádio, ondas curtas,

no sentido de uma intromissão: uma onda que, eventualmente, em suas oscilações, frequenta outra onda, ao estar, por instantes, na mesma frequência que a outra. É uma re-

${ }^{10} \mathrm{O}$ Grupo de Articulação do LS agradece a presença generosa da professora Maria Fernanda Petroli Frutuoso, do curso de nutrição da UNIFESP que, além de várias interferências no LS, integrou o coletivo de curadoria, trabalhou ativamente em montagens, atuou no Cabeça Dizpensa, no projeto $A$ alma é um estômago, além de fazer conosco o bolo antropofágico recheado com açúcar impalpável que é o nome de um tipo de açúcar geralmente feito com açúcar de confeiteiro moído com maisena. 
lação não programada e inevitável, tanto quanto o é o fim inesperado desta justaposição. Um ocupa o outro: simplesmente ocupação, porque seus movimentos ondulatórios assim o exigem (INFORSATO, 2010, p. 198).

A intervenção pode supor a aplicação de certos modelos, ideologemas, simbolizações definidas. Nesse jogo, a intervenção procuraria transformar as experiências numa determinada direção. Tende-se a querer subir a um patamar elevado, a querer luz, a realizar uma missão. Em contraste, interferências podem lidar com delicadezas, sutilezas que tentam não se sobrepor às situações, abrindo-se a direções não pré-estabelecidas (ORLANDI, 2012).

Uma intervenção simplificadora pode ser aquela que incide "sobre" a complicação dos casos, das experiências, dos equipamentos, das ruas; incide ali uma ordenação que acachapa as complexidades. Outro problema: um voluntarismo pode enredar as intervenções e interferências. Daí a questão do "dar certo" - sempre ligada a modelos e parâmetros - e uma demanda de controle do resultado, como imaginar que se possa preparar uma interferência com um tiro único, sem agenciar de novo, escavar mais embaixo, e, se não "deu agora", desconfiar de sua estratégia, e, se deu bem demais desconfiar também. Lawrence (2012, p. 37), em seu Estudos sobre a literatura clássica americana, escreveu: "o que achamos que fazemos não importa muito. Na verdade, nunca sabemos realmente o que estamos fazendo. [...] Somos os atores, nunca inteiramente os autores de nossos próprios atos ou obras".

As interferências não reivindicam total compreensão. Interferência é produção de subjetividade - conhecimento vivo que não passa necessariamente pelo "espelho da consciência” (NIETZSCHE, 2001, p. 248-249). Interessa um rigor nas ligações e montagens das interferências vindas de curadorias que criem um campo de gestão e gestação coletiva, espaços para fazer e desdobrar juntos ideias, mixá-las e recombiná-las.

Interferência e produção de pensamento pedem um "para nada" que é insuportável na ambiência universitária ou na dos serviços. Pedem que se faça um exercício, uma tentativa-experiência de "desastre", de perder o astro - no sentido de algo que guia -, não se tratando das chamadas experiências exitosas, demasiadamente predeterminadas. Isso envolve ligações complexas, experimentações sem garantias, não necessariamente projetos com suas intencionalidades. Pede talvez uma leveza e inteligência de outra ordem que não compõem com o arrivismo e a meritocracia - podendo implicar uma gratuidade que não se inscreve na lógica da comunicação ou da finalidade; um jogo esvaziado precisamente da finalidade, uma espécie de "para nada" que não lhe retira, mas justamente imprime intensidade. $\mathrm{Na}$ ausência de finalidade podem instaurar-se experiências que ativam o corpo-desvago como possibilidade de invenção de si.

\section{Um exemplar:}

[...] interferência em uma aula, um auditório foi interditado; todos ficaram fora, as cadeiras foram empilhadas, livros foram congelados dentro de enormes barras de gelo - era possivel vê-los por fora, inclusive uma revista Mente e Cérebro -, baldes de areia, um rebanho pastando foi projetado o tempo todo em que circulávamos pelos espaços, o auditório estava com pouca luz, um homem chafurdava no chão em uma espécie de chiqueirinho tão feito de jornais quanto ele; duas moças dançavam e não cansavam de cortar e ajustar os cabelos; outro passeava ao léu, de sunga; sons de bocas e gemidos, murmúrios. Houve sustos, não houve conversa ao final.

Trata-se paradoxalmente de um trabalho e "desobra" (não fazer obra) (INFORSATO, 2010): nada de sucesso, de convocar sentimentos ou de fazer analogias. Também nada de "distraídos venceremos" - não se tratava de vencer ou chegar lá - talvez, sobretudo, falhar, falhar de novo, falhar melhor. ${ }^{11}$

\section{A verdade do corpo}

A experiência se deu no Laboratório de Sensibilidades. Era um dia atípico de avaliação conduzida por um grupo de egressos e alunos de quarto e quinto ano, cada qual vinculado de uma forma às aulas que, em um dado momento de suas graduações, lançaram-lhes problematizações com as artes, subjetivação contemporânea, pondo em xeque construções naturalizadas: o psicológico e a própria noção de homem.

De antemão esclarecidos sobre a proposição mais "corporal" do dia, ocorreram experimentações que envolviam desvios sensoriais e formas inauditas de se relacionar com os conceitos e questões tratados no decurso do semestre. Essa aposta fugia à lógikca cerebral já tão exercitada no meio acadêmico. Houve desinteresse e pouca receptividade. Para muitos, o tempo gasto com essas oficinas poderia ser melhor empregado. Outros relatavam um desconforto com atividades que envolvessem corpos.

Em um meio em que a preocupação majoritária era produzir um material ${ }^{12}$ que conciliasse boas articulações e demonstrasse domínio acerca das ligações conceituais, eis que irrompe uma provocação que, ainda que pouco ou nada tenha servido como argumento favorável à experimentação, remeteu a algo para além daquela sala e do motivo da reunião. corpo?"

Disseram: "Alguém tem experiência fora do

Um atlas anatômico é uma produção estética e ética, politicamente determinada. Um atlas anatômico parece algo neutro e útil; ao mesmo tempo ele não é a verdade de um corpo. É produção de uma certa realidade operando com um modelo de corpo. E ela não é sem direção e/ou efeitos ético-clínicos, e implica as terapêuticas. Não é um corpo no atlas anatômico, é o corpo estilo greco-romano dos desenhos da biomedicina, obviamente uma representação que também nos auxilia e leva em certa direção.

\footnotetext{
${ }^{11}$ Referindo-se a expressividade romântica nas artes, Samuel Beckett afirma que o pintor Bran Van Velde foi o primeiro a desistir desse automatismo estetizado denominado expressão, o que ele considerou uma fidelidade ao fracasso, um falhar como ninguém mais ousou falhar (BECKETT, 1949/2001).

${ }^{12} \mathrm{O}$ referido material é um diagrama produzido na avaliação dos módulos Constituição e emergência do psicológico que integram o curso de graduação em Psicologia da UNIFESP.
} 
As imagens do artista Walmor Corrêa, ${ }^{13}$ impressas em tamanho A3 e expostas no campus da universidade, apresentam minuciosos mapas anatômicos com um grau enorme de detalhamento, utilizando os signos e verdades da anatomia para criar uma imagem verossímil, isto é, plausível, com efeito de verdade. E sempre temos isso, tão-somente, o verossímil - que parece verdadeiro, que produz efeito de verdade. Walmor Corrêa produz um mapa anatômico de uma sereia com os órgãos descritos em detalhe, descrições de um bebê-sereia no útero, a panturrilha descrita e aberta do Curupira.

A palavra alemã Unheimlich, título desta série de imagens, tem sido traduzida como "o inquietante" ou ainda "o estranho-familiar", dentre outras possíveis. Com Freud (1919/2010), ela comparece em discussões a respeito da sensação de assombro ou estranheza que por vezes envolve coisas conhecidas e familiares. Na série de Walmor Corrêa, as imagens da exposição - dissecações de seres inventados, aliás, como todos - não se separam dos processos artísticos, científicos e metodológicos que constituem as próprias figuras, o que, no limite, possibilita colocar em jogo noções e imagens de todos os corpos, corpos quaisquer - também produzidas. $\mathrm{O}$ desencaixe que pode provocar essas imagens ajuda a pensar: "O que é que junta em mim as coisas que leio e vejo? Que forças em mim me fazem ver isso? Que forças em mim me fazem expressar 'assim o que estou pensando'? Que forças já me dominam? Com que forças me alio?" (ORLANDI, 2012, online).

\section{Interferir-se}

Em que medida as interferências - que exigem um rigor e tentativas - deslocam percepções, produzem micropercepções? Nas interferências estético-políticas pode haver um apelo fácil ao já sabido, ao sensacional, ao espetacular ou sentimental. Interessa considerar o convite forte à autopromoção, à busca de sucesso e "gerenciamento empresarial de si" na universidade, nas artes, nos serviços etc.; são musculaturas que podem ser acionadas com as experimentações, sustentando modos de trabalhar e pesquisar. Hoje a lógica da empresa - que não está em um único lugar - é um gás espalhado que coloniza o que chamamos de nosso desejo. É antes de tudo um modo de fazer que tenta tomar o que é federal, estadual e municipal com incidências as mais diversas nas artes, na pesquisa, na saúde e na clínica com seus prêmios, excitações e saudáveis motivações. Sobretudo é um fluxo de jogo metaestável espraiado na tessitura subjetiva. Nesse jogo de interferências estéticas pode haver uma espécie de "guerrilha contra nós mesmos" ou melhor,

[...] a guerrilha contra as potências maiúsculas - sejam automatismos, empreendedorismos, partidarismos, missionarismos laicos ou quaisquer proeminências transcendentes - que nos invadem, que nos habitam ou que nos habilitam na sacanagem muito contemporânea de certo servilismo (ORLANDI, 2006, p. 66).

\footnotetext{
${ }^{13}$ Algumas destas imagens da série Unheimlich estão disponíveis no blog do Laboratório de Sensibilidades (2016c).
}

\section{Finalmente}

Pesquisar contra si e encontrar o que não aceitamos na experiência do método

Gels

Meus ombros pesados adentram a sala. Colocam-se ao lado de muitos outros ombros e nucas cheios de nós. Costumamos carregar todas as aulas e trabalhos acima dos membros, por aqui. Uma biopolitica. As testas estão enrugadas. Silêncio. Blablablá e... "podemos escolher os campos, então?" Sim! As testas se dobram ainda mais. Penso na política das testas enquanto a discussão se desenrola. Uma voz enuncia, como cenário possível de ação "Arte no Dique"14 e também enrugo a testa. Dois braços se erguem. Duas vagas disponíveis. Cada braço ocupa uma vaga e resolvemos. Ombros e testas, agora tranquilos, se levantam e seguem rumos.

No primeiro encontro do grupo de estudantes ${ }^{15}$ do terceiro ano, ocorrido no LS, levo os sentidos às sensibilidades. Espaço que produz corpos. Cria outros órgãos e desorganizações. Lá, o tempo é outro e as pessoas não são as mesmas. Piso e meu passo já muda de jeito, recordando as lembranças daquela sala vazia e, por isso mesmo, cheia de tudo. Sala de mundos que, fora de lá, são mudos. Quase inaudiveis. Imperceptiveis. Sensíveis. Encontro-me com mais uns doze pares de olhos. "Vocês por aqui?!" Coexistimos, ainda preservando distâncias. Até que uma chegada se anuncia. Movimentos. Correria. Vaptvupt. Todo mundo se apronta para a recepção. As luzes se apagam e é dada a largada.

A convidada começa seu caminho com pés de pesquisadora e nós permanecemos grudados ao chão, como se nos fundissemos ao piso e incorporássemos obstáculos. Que momento delicado. Inicia-se a dança de bambolês, cones, braços, ouvidos. Percursos sonoros. Percalços. Vou me aproximando mais de cada vida ali presente. E somos povoados, finalmente, e de luzes acesas, de novos sentidos nos olhos. Veio-me uma frase: "o olho pensa". E quantos impensados compartilhamos. Teve verde, preto, castanho, azulzinho. Histórias azuis, sentimentos castanhos. Duas pequenas bolinhas logo acima do nariz que me sorriam. Sorri de volta um sorriso que me veio do estômago. E seguimos ouvindo e dizendo histórias, ao mesmo tempo em que gestávamos novas contações. Geríamos, girávamos. Escutei-me falando de minha história com a arte pela primeira vez na vida. Primeira vez que absorvia isso pelos ouvidos. Entrava pelo ouvido e saía não sei por onde.

Jogamos mais algumas palavras na roda $e$ descobrimos que tudo o que dissemos não escapou pela porta nem pelas janelas da sala. Continuaram pairando pelos vãos dos nossos dedos, pelas brechas entre uma perna e outra, preenchendo todos os espaços vazios dos corpos.

Há, então, que se tomar cuidado com as palavras mortas. Mas como é que se vivifica uma escrita, uma frase, um ponto? Talvez perfurando com perguntas.

Estou disposta a encontrar aquilo que não aceito?

${ }^{14}$ Trata-se de uma ONG da Zona Noroeste de Santos, que promove atividades com as artes e os moradores do bairro, e, especialmente das palafitas do Dique da Vila Gilda.

${ }^{5}$ Estudantes que cursavam o módulo Práticas Clínica Integrada do Eixo Trabalho em Saúde no ano de 2016 


\section{O fim está no começo e, no entanto, continua-se $e^{16}$}

No dia seguinte à segunda votação favorável à Proposta de Emenda Constitucional (PEC) $241^{17}$ na Câmara dos deputados federais, que congela por 20 anos os gastos públicos (saúde e educação inclusos), uma lona preta de vinte metros atravessou corredores do edifício central do campus universitário como uma onda de ressaca, levada pelas bordas por professores e estudantes. ${ }^{18}$ Ruidosa, sem palavras, descia e subia escadas, mar indócil, revolto, inconformado.

No princípio era a ação: ${ }^{19}$ acéfala, desvaga.

\section{Referências}

ANTUNES, A. Palavra Desordem. São Paulo: Iluminuras, 2002.

BECKETT, S. Três diálogos com Georges Duthuit (1949). In ANDRADE, F. S. Samuel Beckett: o silêncio possível. São Paulo: Ateliê editorial, 2001. p. 173-182.

BECKETT, S. Fim de partida. São Paulo: Cosac e Naif, 2002.

BURROUGHS, W. A Revolução Eletrônica. Lisboa: Vega, 1994.

CASETTO et al. Laboratório de Sensibilidade, Inteligência coletiva e Clube dos saberes. In: COLÓQUIO DE PSICOLOGIA DA ARTE, 2., 2007, São Paulo. Mesa X - Trânsito do Sensível. São Paulo: USP, 2007. Disponível em: <http://www.ip.usp.br/ laboratorios/lapa/versaoportugues/2c78a.pdf>. Acesso em: 7 out. 2016 .

DELEUZE, G.; GUATARRI, F. Mil platôs: capitalismo e esquizofrenia. Rio de Janeiro: Ed. 34, 1996. v. 3.

FERRAZ, M. C. F. Nietzsche: esquecimento como atividade. Cadernos Nietzsche, Porto Seguro, n. 7, p. 27-40, 1999. Disponível em <http://gen.fflch.usp.br/sites/gen.fflch.usp.br/ files/upload/cn 07 02\%20Ferraz.pdf>. Acesso em 17 set. 2016.

FREUD, S. O inquietante (1919). São Paulo: Companhia das Letras, 2010. Obras completas, v. 14.

FREUD, S. Totem e tabu (1912-1913). São Paulo: Companhia das Letras, 2012. Obras completas, v. 11.

HENZ, A. O. et al. A compreensão é um dos níveis de leitura: experimentações e sensações - itinerários de literatura e clínica. Interface (Botucatu), Botucatu, v.16, n. 40, jan./mar. 2012. Cross ${ }^{\text {Ref. }}$

INFORSATO, E. A. Desobramento: constelações clínicas e políticas do comum. 2010. Tese (Doutorado em Eduação)Faculdade de Educação da Universidade de São Paulo, São Paulo, 2010. Disponível em: <http://www.teses.usp.br/teses/ disponiveis/48/48134/tde-22042010-104547/en.php>. Acesso em 17092016.

LABORATÓRIO DE SENSIBILIDADES. Laboratório de Sensibilidades 2007: primeiro dia. 7 dez. 2011. Disponível em:

${ }^{16} \mathrm{Cf}$. Beckett (2002, p. 128).

${ }^{17}$ A PEC 241 foi aprovada na câmara de deputados em 26/10/2016. Acerca da aprovação da proposta de Emenda à Constituição no 241/2016, ver: <http:// www.redebrasilatual.com.br/politica/2016/10/pec-do-teto-dos-gastos-publicose-aprovada-em-2o-turno-falta-votar-destaques-3820.html $>$.

${ }^{18}$ Confira os vídeos da interferência Comum da Lona Preta com Luiz Orlandi na UNIFESP-BS (LS, 2016d).

${ }^{19}$ Ver especialmente a referência de Freud (1912-1913/2012, p. 157) ao Fausto de Goethe na última frase de Totem e Tabu. com/2011/12/07/laboratorio-de-sensibilidades-2007-primeirodia-4/>. Acesso em: 17 set. 2016.

LABORATÓRIO DE SENSIBILIDADES. A alma é um estômago, isto não é uma metáfora: comidas, digestões alegres, dispepsias políticas-ressentimentos e a saúde de certas anorexias. 7 ago. 2012. Disponível em: <https:// laboratoriodesensibilidades.wordpress.com/2012/08/07/aalma-e-um-estomago-isto-nao-e-uma-metafora-comidasdigestoes-alegres-dispepsias-politicas-ressentimentos-e-asaude-de-certas-anorexias/>. Acesso em: 18 set. 2016.

LABORATÓRIO DE SENSIBILIDADES. A alma é um estômago: relato de um visitante (instalação). 29 abr. 2016a. Disponível em: <https://laboratoriodesensibilidades. wordpress.com/2016/04/29/no-laboratorio-de-sensibilidadesa-instalacao-a-alma-e-um-estomago-relato-de-um-visitante/>. Acesso em: 17 set. 2016.

LABORATÓRIO DE SENSIBILIDADES. Cabeça Dizpensa: grupo de articulação do laboratório de sensibilidades. 27 set. 2016b. Disponível em: <https://laboratoriodesensibilidades. wordpress.com/2016/09/27/cabeca-dizpensa-grupo-dearticulacao-do-laboratorio-de-sensibilidades/>. Acesso em: 8 out. 2016.

LABORATÓRIO DE SENSIBILIDADES. Um atlas anatômico é uma produção estética e ética, politicamente determinada. 21 set. 2016c. Disponível em: <https://laboratoriodesensibilidades. wordpress.com/2016/09/21/um-atlas-anatomico-e-umaproducao-estetica-e-etica-politicamente-determinada-abaixoas-obras-do-artista-walter-correa/>. Acesso em: 21 set. 2016.

LABORATÓRIO DE SENSIBILIDADES. Manifestação Hoje: Comum da Lona Preta com Luiz Orlandi na UNIFESP-BS. 26 out. 2016d. Disponível em: $<$ https://laboratoriodesensibilidades. wordpress.com/2016/10/26/manifestacao-hoje-comum-dalona-preta-com-luiz-orlandi-na-unifesp-bs-veja-os-microvideos/>. Acesso em: 8 nov. 2016.

LAWRENCE. D. H. Estudos sobre a literatura clássica americana. Rio de Janeiro: J. Zahar, 2012.

MANTERO, V. Vamos sentir falta de tudo aquilo que não precisamos. Disponível em: <http://www.youtube.com/ watch? feature $=$ player_embedded $\& v=0 j t D-31$ hinw $>$. Acesso em: 25 set. 2016.1 vídeo.

NIETZSCHE, F. Gaia Ciência. São Paulo: Companhia das Letras, 2001.

ORLANDI, L. B. L. Reich em "O Anti-Édipo". Revista Reichiana, São Paulo, n. 15, p. 56-66, 2006.

ORLANDI, L.B.L. Orlandi \& Giacóia. 18 mar. 2012. Disponível em: <https://www.youtube.com/watch?v=Hem6s9cvJKI>. Acesso em: 17 set. 2016.1 vídeo.

PAPE. L. O Divisor. Disponível em: <https://youtu.be/ pipCLdQS7to>. Acesso em: 20 out. 2013. 1 vídeo.

PEC 241 é aprovada em segundo turno na Câmara. Rede Brasil Atual. 26 out. 2010. Disponível em: <http://www. redebrasilatual.com.br/politica/2016/10/pec-do-teto-dosgastos-publicos-e-aprovada-em-2o-turno-falta-votardestaques-3820.html>. Acesso em: 31 out. 2016.

SERRES, M. Polegarzinha. Trad. Jorge Bastos. Rio de Janeiro: Bertrand Brasil, 2013

Recebido em: 12 de novembro de 2016 Aceito em: 11 de maio de 2017

Fractal, Rev. Psicol., v. 29 - n. 2, p. 96-102, 2017 